\title{
Pelatihan Matematika Dasar Menggunakan Media Animasi Jarimatika Bagi Anak-Anak TPQ Masjid Baitul Muhsinin Sumbang
}

\author{
Yuli Purwati ${ }^{*}$, Esa Damayanti ${ }^{2}$, Imung Dwi Upaya ${ }^{3}$ \\ ${ }^{1,3}$ Program Studi Informatika, Universitas Amikom Purwokerto, Indonesia \\ ${ }^{3}$ Program Studi Sistem Informasi, Universitas Amikom Purwokerto, Indonesia \\ Email: ${ }^{1}$ yulipurwati@amikompurwokerto.ac.id, ${ }^{2}$ Esasagab@gmail.com, ${ }^{3}$ Immungdwi22@gmail.com
}

\section{INFORMASI ARTIKEL}

\section{Data artikel:}

Naskah masuk, 21 Desember 2020

Direvisi, 27 Januari 2021

Diiterima, 6 Februari 2021

\section{Kata Kunci:}

Matematika Dasar, Media Animasi, Jarimatika,

\begin{abstract}
ABSTRAK
Abstract- The children's activities at the TPQ Baitul Muhsinin Mosque are currently only carried out 3 times a week so that on other days there are no activities for children at the mosque, eventually some of them choose to play gadgets or watch television. To fill in activities other than reciting recitation and filling in activities on empty days, the solution offered in this service activity is to provide basic math training for children at TPQ by using the finger animation media. This training was chosen because numeracy skills have many benefits for children, including enabling children to better understand the universe and the laws that apply in it, enabling children to plan and evaluate well as adults, enabling children to make designs and constructions correctly., teach children to be fair, train children to shop properly and not easily cheated and many other benefits. The method chosen in the animation media is the Jarimatika method, which is one way to perform arithmetic operations. It is called Jarimatika because it is done by using your fingers to help solve Arithmetic. With this training, it is hoped that the children's activities at the TPQ Baitul Muhsinin Sumbang Mosque will be more active and varied because there are other activities that can be done besides reciting the Koran, they can use animation media at home to learn by involving parental participation, The results of this training activity the children were able to solve addition and subtraction problems using the Jarimatika method quickly and precisely and was fun because they used their fingers to count.
\end{abstract}
Abstrak- Kegiatan anak-anak di TPQ Masjid Baitul Muhsinin saat ini hanya dilakukan hanya kegiatan mengaji. Untuk mendukung kegiatan di sekolah dan menambah ketrampilan anak-anak dibidang lain selain mengaji, maka solusi yang ditawarkan dalam kegiatan pengabdian ini adalah memberikan pelatihan matematika dasar untuk anak-anak di TPQ dengan menggunakan media animasi jarimatika. Pelatihan ini dipilih karena keterampilan berhitung memiliki banyak manfaat bagi anak diantaranya membuat anak dapat lebih memahami alam semesta dan hukum-hukum yang berlaku di dalamnya, membuat anak dapat melakukan perencanaan dan evaluasi 
dengan baik saat dewasa nanti, membuat anak dapat membuat rancangan dan konstruksi dengan benar, mengajarkan anak berlaku adil, melatih anak bisa berbelanja dengan benar dan tidak mudah ditipu dan masih banyak lagi manfaat lainnya. Metode yang dipilih dalam media animasi adalah metode jarimatika yang merupakan salah satu cara untuk melakukan operasi hitung. Disebut Jarimatika karena dilakukan dengan memanfaatkan jari-jari tangan untuk alat bantu menyelesaikan Aritmatika. Dengan adanya pelatihan ini diharapkan kegiatan anak-anak di TPQ Masjid Baitul Muhsinin Sumbang menjadi lebih aktif dan bervariasi karena ada kegiatan lain yang bisa dilakukan selain mengaji, media animasi dapat mereka gunakan dirumah untuk belajar dengan melibatkan partisipasi orang tua, Hasil kegiatan pelatihan ini anak-anak mampu menyelesaikan soal-soal penjumlahan dan pengurangan menggunakan metode jarimatika dengan cepat dan tepat serta menyenangkan karena mereka menggunakan jari-jari saat berhitung.

\section{Korespondensi:}

\section{Yuli Purwati}

Program Studi Informatika, Universitas Amikom Purwokerto

Jl. Letjen Pol Sumarto1 Purwanegara, Purwokerto Utara, Banyumas., Indonesia

\section{PENDAHULUAN}

Pelajaran matematika dianggap sebagai mata pelajaran yang sulit dan membosankan sehingga banyak siswa yang tidak menyukai matematika (Dai et al. 2019). Ada beberapa permasalahan yang terjadi dalam proses pembelajaran matematika di sekolah diantaranya yang berkaitan dengan karekteristik pelajaran matematika seperti objeknya yang abstrak, konsep dan prinsipnya yang berjenjang, serta prosedur dalam mengerjakan soal matematika yang banyak memanipulasi bentuk-bentuk seringkali membuat siswa mengalami kesulitan (Risnawati, 2013).

Meski demikian matematika merupakan salah satu satu pengetahuan dasar yang berperan penting dalam membentuk siswa agar dapat berfikir secara ilmiah (Sitio, 2017). Selain itu ada banyak sekali manfaat dari keterampilan matematika diantaranya:

a. Membuat anak dapat lebih memahami alam semesta dan hukum-hukum yang berlaku di dalamnya; b. Membuat anak dapat melakukan perencanaan dan evaluasi dengan baik saat dewasa nanti;

c. Membuat anak dapat membuat rancangan dan konstruksi dengan benar;

d. Mengajarkan anak berlaku adil;

e. Melatih anak bisa berbelanja dengan benar dan tidak mudah ditipu.

Begitu pentingnya ketrampilan ini, sehingga orang tua secara sadar maupun tidak seringkali 'memaksa' anak untuk segera menguasai kemampuan berhitung baik (Li, Antonenko, and Wang 2019). Salah satu cara agar anak bisa belajar matematika dengan cara menarik dan menyenangkan yaitu dengan menciptakan suasana belajar yang santai, nyaman dan interaktif (Wanti and Tripustikasari 2019). Dengan munculnya perasaan nyaman dan interaktif akan dapat memunculkan rasa percaya anak pada dirinya bahwa matematika itu tidak sulit (Purwati and Perdanawanti 2019).

Jarimatika merupakan salah satu cara melakukan operasi hitung. Menurut Wulandani 
dalam Afriani (2019) jarimatika merupakan metode berhitung yang dilakukan dengan memanfaatkan jari-jari tangan untuk alat bantu menyelesaikan Aritmatika dalam hal ini proses berhitung KaBaTaKu (Kali - Bagi - Tambah dan Kurang) sehingga dapat menciptakan proses belajar yang menyenangkan dan interaktif (Alam, Az-Zahra, and Rokhmawati 2019).

Anak-anak di komplek perumahan Ciberem, Sumbang melakukan kegiatan mengaji di masjid setiap seminggu 3 kali yakni hari Kamis, Jum'at dan Sabtu, saat menunggu ustadzah datang kegiatan anak-anak adalah mewarnai, di hari lain yang tidak ada jadwal mengaji anak-anak tidak punya kegiatan lain, jadi hanya diisi dengan main gadget atau nonton TV di rumah masing-masing karena umumnya tidak mengikuti les di luar sekolah. Gambar 1. merupakan aktivitas anak-anak TPQ masjid Baitul Muhsinin.

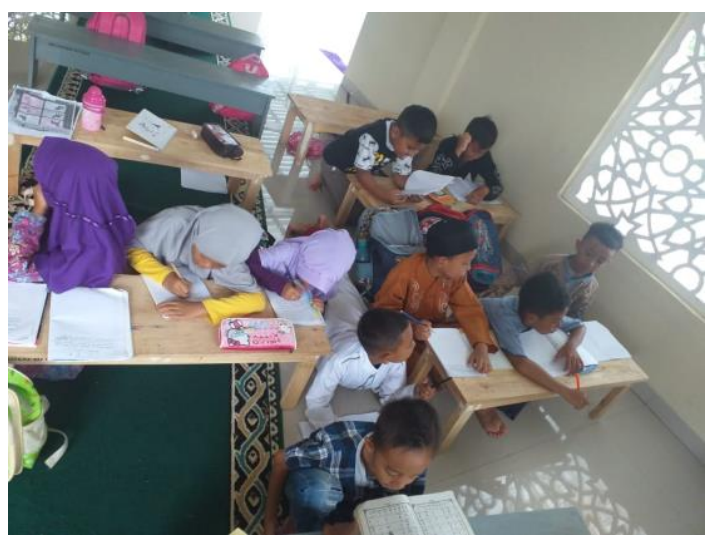

Gambar 1. Aktivitas anak-anak TPQ Masjid Baitul Muhsinin Sumbang

Untuk memberikan perbaikan dalam kegiatan di TPQ Masjid Baitul Muhsinin Sumbang, pengabdian ini dilakukan untuk memberikan solusi dengan cara melakukan pelatihan matematika dasar menggunakan media animasi jarimatika bagi anak-anak usia 3-10 tahun sehingga mereka memiliki kegiatan positif lain selain mengaji atau bisa juga dilakukan saat menunggu ustadzah datang.

Matematika dipilih karena bisa digunakan untuk mendukung kegiatan mereka di sekolah, selain itu juga ada banyak manfaat dari belajar matematika bagi anak. Nilai lebih dari metode jarimatika adalah karena jarimatika memberikan visualisasi proses berhitung. Hal ini akan membuat anak mudah melakukannya. Gerakan jari-jari tangan akan menarik minat anak karena mungkin mereka menganggapnya lucu dan mereka akan melakukannya dengan gembira (Riani, Hindun, and Krisno Budiyanto 2015). Jarimatika relatif tidak memberatkan memori otak saat digunakan. Alatnya tidak perlu dibeli, tidak akan pernah ketinggalan, atau terlupa dimana menyimpannya.

Media animasi jarimatika digunakan sebagai alat pendukung agar anak tertarik dan diharapkan dengan adanya animasi akan memudahkan mereka membahami bagaimana berhitung menggunakan metode jarimatika. Animasi ini juga bisa mereka gunakan dirumah menggunakan gadget sehingga mereka mempunyai kegiatan positif agar tidak selalu nonton televisi atau bermain game di gadget (Purnama 2016).

Target yang diharapkan dari kegiatan pengabdian Amikom Mitra Masyarakat ini adalah sebagai berikut: 1) Kegiatan anak-anak di TPQ Masjid Baitul Muhsinin Sumbang menjadi lebih aktif dan bervariasi karena ada kegiatan lain yang bisa dilakukan selain jadwal mengaji yang hanya 3 kali seminggu; 2) Media Animasi dapat diputar di gadget sehingga bisa mereka gunakan dirumah untuk belajar dengan melibatkan partisipati orang tua; 3) Metode jarimatika akan lebih menyenangkan untuk belajar matematika dasar bagi anak usia 3-10 tahun karena tidak memberatkan memori otak.

\section{METODE PELAKSANAAN}

Kegiatan pengabdian masyarakat ini dibagi menjadi tiga tahapan kegiatan,yaitu :
a. Tahap Persiapan
b. Tahap Pelaksanaan
c. Tahap Penutup

Pada tahapan persiapan ini dilakukan analisis permasalahanan sehingga terdefinisi masalah yang akan diselesaikan, kemudian menyiapkan semua peralatan yang akan 
digunakan pada saat kegiatan pengabdian masyarakat. Pada tahapan pelaksanaan pengabdian masyarakat maka dilakukan kegiatan mempresentasikan modul pelatihan dari awal sampai dengan akhir. Pada tahap penutup, dilakukan evaluasi dengan memberikan soal latihan. Langkah-langkah kegiatan dapat dilihat pada gambar 2 berikut:

\begin{tabular}{|l|}
\hline Persiapan: \\
- Melakukan analisis permasalahan \\
- Persiapan sarana dan prasarana (televisi \\
- Penyiapkan modul pelatihan \\
Pelaksanaan tempat kegiatan \\
- Mempresentasikan kepada siswa tentang \\
metode jarimatika dengan cara memutar \\
- video animasi jarimatika \\
- Mengajarkan penjumlahan dengan \\
- Menggunakan metode jarimatika \\
- Menyamakaikan soal-soal penjumlahan \\
dengan jarimatika \\
- Mengerjakan soal-soal pengurangan \\
dengan jarimatika \\
pengadakan test untuk melihat hasil dari
\end{tabular}

Penutup:

Melakukan evaluasi dengan cara memberikan soal-soal penjumlahan dan pengurangan yang dikerjakan menggunakan metode jarimatika

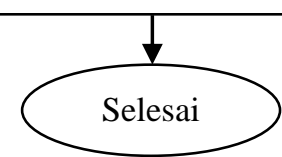

Gambar 2. Tahapan Kegiatan PKM

\section{HASIL DAN PEMBAHASAN}

\section{a. Persiapan}

Sebelum kegiatan dilaksanakan maka dilakukan persiapan-persiapan sebagai berikut:

1) Menentukan waktu pelaksanaan dan lama kegiatan Amikom Mitra Masyarakat.

2) Melakukan koordinasi dengan penanggung jawab TPQ Masjid Baitul Muhsinin
Sumbang terkait dengan pelaksanaan kegiatan Amikom Mitra Masyarakat.

3) Melakukan sosialisasi kepada mitra khususnya warga perumahan Puri Kencana dan Agapro yang anak-anaknya mengaji di TPQ masjid Baitul Muhsinin Sumbang tentang jadwal pelaksanaan dan mekanisme kegiatan yang akan dilaksanakan.

\section{b. Pelaksanaan}

Pelaksanaan kegiatan pengabdian dilakukan selama 2 hari yakni tanggal 18-19 Dsesmber 2020 dengan menggunakan televisi yang digunakan untuk memutar animasi jarimatika untuk belajar matematika dasar bagi anak-anak TPQ Masjid Baitul Muhsinin Sumbang. Pelatihan dibantu oleh 2 orang mahasiswa Universitas Amikom Purwokerto dan penanggung jawab TPQ. Gambar 3, dan 4 merupakan foto pelaksanaan kegiatan.

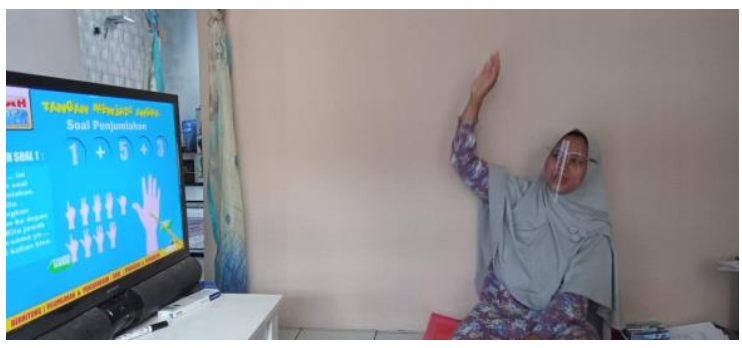

Gambar 3. Kegiatan pemutaran video animasi jarimatika

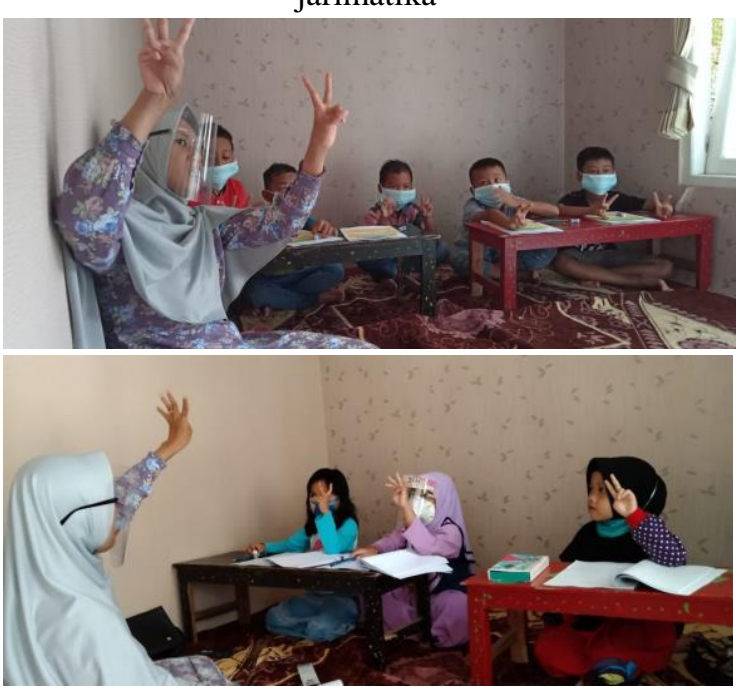

Gambar 4. Kegiatan penyampaian materi

\section{c. Evaluasi}

Evaluasi dilakukan dengan menguji pemahaman siswa tentang lambang-lambang 
jarimatika serta memberikan soal-soal penjumlahan dan pengurangan menggunakan metode jarimatika. Gambar 5 merupakan foto kegiatan menjawab soal dan gambar 6 merupakan salah satu contoh soal yang diberikan kepada peserta.

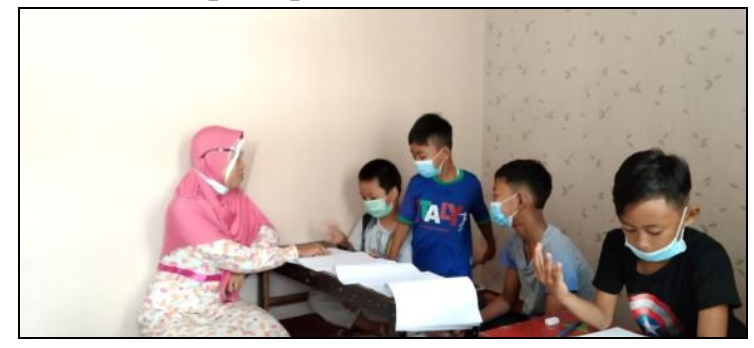

Gambar 5. Kegiatan menjawab soal dengan metode jarimatika

\begin{tabular}{|l|l|}
\hline \multicolumn{2}{|l|}{$\begin{array}{l}\text { Nama Peserta : } \\
\text { Jumlan Jawaban Benar: }\end{array}$} \\
\hline $2+1+1=$ & $32+11=$ \\
\hline $3+1-1=$ & $12+31=$ \\
\hline $1+2+1=$ & $10+23-12=$ \\
\hline $2+2-1=$ & $34-12+21=$ \\
\hline $4-1+1-3=$ & $24-3+11=$ \\
\hline $10+10+20-30=$ & $14+20-13+10=$ \\
\hline $10+30-20+10=$ & $13+21+10-32=$ \\
\hline $20+20-30+10=$ & $22-10+2+20=$ \\
\hline $30-10+20-10-30=$ & $4+20-13+22-10=$ \\
\hline $10+20+10-30+20=$ & $2+11-3+14+20=$ \\
\hline
\end{tabular}

Gambar 6. Soal penjumlahan \& pengurangan

Pada saat mengerjakan soal-soal matematika penjumlahan dan pengurangan, peserta sudah mulai terbiasa menggunakan jari-jari mereka untuk menghitung dan menemukan jawaban yang benar dengan ratarata waktu menjawab kurang dari 1 menit. Tabel 1 merupakan rangkuman umpan balik pemahaman peserta terhadap materi jarimatika yang diberikan.

Tabel 1. Rekapitulasi pemahaman peserta terhadap materi jarimatika

\begin{tabular}{ccc}
\hline Umpan balik & $\begin{array}{c}\text { Jml } \\
\text { Anak }\end{array}$ & Prosentase \\
& 13 & \\
\hline Pemahaman peserta & 13 & \\
\hline
\end{tabular}

1. Memahami lambang
jarimatika satuan

2. Memahami lambang $13 \quad 100 \%$ jarimatika puluhan

3. Menjawab soal-soal $11 \quad 90 \%$ penjumlahan dengan metode jarimatika dengan tepat

4. Menjawab soal-soal 11
pengurangan dengan
metode jarimatika
dengan tepat

Berdasarkan hasil analisis umpan balik yang diperoleh dapat disimpulkan bahwa peserta mampu memahami dan mengingat lambang-lambang jarimatika dan mampu mengerjakan soal penjumlahan dan pengurangan menggunakan metode jarimatika, hanya peserta yang usianya masih sangat kecil yang masih kesulitan mengerjakan soal-soal yang diberikan.

\section{KESIMPULAN}

Berdasarkan pengamatan dan pemberian pertanyaan dan analisis umpan balik yang dilakukan selama kegiatan berlangsung, kegiatan pelatihan matematika dasar menggunakan media animasi jarimatika bagi anak-anak TPQ Masjid Baitul Muhsinin Sumbang memberikan hasil sebagai berikut:

1) Peserta mengetahui mengenai pemanfaatan media animasi jarimatika untuk melatih ketrampilan matematika

2) Peserta dapat memahami materi video Animasi Jarimatika dengan baik serta dan antusias dalam mengerjakan soal-soal latihan yang diberikan.

3) Penggunaan video animasi jarimatika untuk pelatihan matematika bagi anak-anak TPQ masjid Baitul Muhsinin Sumbang dapat 
memudahkan peserta dalam mengerjakan soal-soal latihan matematika.

4) Kegiatan dihadiri oleh 13 peserta. Yang dibagi menjadi 3 kelompok. Tanggapan dari peserta sangat positif dan antusias karena mereka merasakan manfaat dari kegiatan Amikom Mitra Masyarakat tentang pelatihan matematika dasar menggunakan media animasi jarimatika bagi anak-anak TPQ Masjid Baitul Muhsinin Sumbang. Tanggapan orang tua juga sangat positif dan mengharapkan program ini dapat dilanjutkan untuk jangka panjang tidak hanya selama kegiatan pelatihan berlangsung saja.

\section{DAFTAR PUSTAKA}

'Alam, Ghasa Faraasyatul, Hanifah Muslimah Az-Zahra, and Retno Indah Rokhmawati. 2019. "Pengembangan Media Pembelajaran Berbasis Multimedia Interaktif Pada Mata Pelajaran Sains Materi Tata Surya Menggunakan Model APPED (Studi Kasus: SD Brawijaya Smart School)." Jurnal Pengembangan Teknologi Informasi dan Ilmu Komputer 3(4): 3832-37. http://jptiik.ub.ac.id/index.php/jptiik/article/view/5047.

Dai, Shengyun et al. 2019. "SeDeM Expert System for Directly Compressed Tablet Formulation: A Review and New Perspectives." Powder Technology 342: 517-27. https://doi.org/10.1016/j.powtec.2018.10. 027.

Li, Jingwei, Pavlo D. Antonenko, and Jiahui Wang. 2019. "Trends and Issues in Multimedia Learning Research in 19962016: A Bibliometric Analysis."
Educational Research Review 28(November 2018): 100282. https://doi.org/10.1016/j.edurev.2019.100 282.

Purnama, Sigit. 2016. "Metode Penelitian Dan Pengembangan (Pengenalan Untuk Mengembangkan Produk Pembelajaran Bahasa Arab)." LITERASI (Jurnal Ilmu Pendidikan) 4(1): 19.

Purwati, Yuli, and Linda Perdanawanti. 2019. "Pelatihan Desain Menggunakan Aplikasi Canva Untuk Anggota Komunitas Ibu Profesional Banyumas Raya." 1(1).

Riani, Sri, Iin Hindun, and Moch. Agus Krisno Budiyanto. 2015. "Pengembangan Media Pembelajaran Berbasis Multimedia Interaktif Untuk Meningkatkan Pemahaman Materi Bioteknologi Modern Siswa Kelas Xii Sma." Jurnal Pendidikan Biologi Indonesia 1(1): 9-16. Wanti, Linda Perdana, and Eka Tripustikasari. 2019. "Pelatihan Komputer Dasar Bagi Kader PKK Dan Posyandu Di Desa Patikraja." Madani : Indonesian Journal of Civil Society 1(1): 17-23.

Afriani, D., Fardila, A., \& Septian, G. D. (2019). Penggunaan Metode Jarimatika Dalam Meningkatkan Kemampuan Berhitung Perkalian Pada Siswa Sekolah Dasar. Journal of Elementary Education, 2(5), 191-196.

Risnawati. (2013). Keterampilan Belajar Matematika. Aswaja Pressindo.

Sitio, T. (2017). Penerapan Metode Jarimatika Untuk Meningkatkan Hasil Belajar Matematika Siswa Kelas I Sdn 003 Pagaran Tapah Darussalam Kabupaten Rokan Hulu. Primary: Jurnal Pendidikan Guru Sekolah Dasar, 6(1), 146. https://doi.org/10.33578/jpfkip.v6i1.4097 